\title{
Prehospital resuscitation of a man with excited delirium and cardiopulmonary arrest
}

\author{
Patrick Joseph Maher, MD*; Mimi Walsh, $\mathrm{PhD}^{\dagger}$; Thomas Burns, $\mathrm{BA}^{\dagger}$; Jared Strote, MD, MS*
}

\section{ABSTRACT}

Features consistent with the syndrome known as excited delirium (ExDS) have been associated with law enforcement restraint-related death. The pathophysiology and exact causative factors of restraint-related death associated with ExDS remain unclear. We present a case of successful field resuscitation of a man with ExDS who experienced cardiopulmonary arrest while being restrained by law enforcement officers. Despite the presence of a severe lactic acidosis on emergency department admission, the patient recovered following prehospital treatment with advanced cardiac life support measures and intravenous sodium bicarbonate, likely in part due to early recognition of the disease process.

\section{RÉSUMÉ}

Les manifestations cadrant avec le syndrome appelé délire actif (DA) sont associées à des décès attribuables à l'application de moyens de contrainte par les forces policières. On ne connaît pas très bien la physiopathologie et les facteurs causaux exacts de la mort associée à l'application de ces moyens dans le contexte du DA. II sera ici question d'un cas de réanimation, réalisée sur place et couronnée de succès, d'un homme en état de délire actif, qui a subi un arrêt cardiorespiratoire pendant qu'il était maîtrisé par les policiers. Malgré la présence d'une forte acidose lactique à I'arrivée au service des urgences, le patient a été réanimé à la suite d'un traitement préhospitalier comportant des moyens énergiques de maintien des fonctions vitales et l'administration de bicarbonate de sodium par voie intraveineuse; l'intervention a probablement réussi grâce en partie à la reconnaissance précoce du processus morbide.

Keywords: cardiac arrest, delirium, metabolic acidosis, physical, prehospital, restraint, resuscitation

Features consistent with the syndrome known as excited delirium (ExDS) have been associated with law enforcement restraint-related death. The syndrome comprises many behaviours and typically involves agitation, delirium, paranoia, seeming imperviousness to pain, and abnormal strength. ${ }^{1}$ For a number of reasons, ExDS in-custody deaths have lead to controversy in both the media and medical literature. Very little is known about the epidemiology, pathophysiology, and causative factors of such deaths; cases frequently involve patients with recreational drug use and/or psychiatric disease; and often deaths involving restraint lead to questions of excessive force. ${ }^{1}$

Research on ExDS in-custody deaths is challenging for many reasons. Epidemiologic data are difficult to obtain, in part because the defining symptoms are often seen in other medical conditions, such as sympathomimetic abuse, and because the ExDS label is often applied retrospectively. Furthermore, given the rarity of the syndrome, a study large enough to accurately define incidence would be difficult to perform. Most such deaths occur in the prehospital setting, where medical personnel and evaluative modalities are not immediately available and where patient agitation further challenges effective evaluation. We present a case of a man exhibiting symptoms of ExDS who was successfully resuscitated in the prehospital setting after law enforcement restraintrelated cardiopulmonary arrest.

\section{CASE REPORT}

Two police officers engaged a 44-year-old man with no past medical history while serving him an arrest warrant for assault. The man answered the door but "was not acting normally" and quickly became

From the *Division of Emergency Medicine, Department of Medicine, University of Washington, and tSeattle Police Department, Seattle, WA.

Correspondence to: Dr. Patrick Maher, Box 359702, 1CT89, Harborview Medical Center, 325 Ninth Avenue, Seattle, WA 98104-2499; maherp@ uw.edu.

This article has been peer reviewed. 
combative, yelling at and resisting the officers. A leg sweep was used to bring the man to the ground. At this point, he began to sweat profusely and scream that he was "all-powerful." A conducted energy weapon was deployed, and the probes were imbedded on the man's left leg and upper back, resulting in what was expected to be a good circuit that would incapacitate his skeletal muscle control. Two cycles discharged from the weapon failed to even briefly control the man's aggressive behaviour. Pain control techniques involving pressure points and joint locks were similarly unsuccessful. The man dragged the officers down a long hallway while they called for backup and was described as having significantly above-normal strength. He was also noted to have "bug eyes" and to grunt throughout the encounter. Ultimately, 10 officers were required to restrain the man, who was placed prone with his hands cuffed behind his back and his legs lashed together with zip ties. The law enforcement officers were concerned that the man was suffering from ExDS and immediately called for medical assistance.

On arrival of basic life support (BLS) care providers, the patient was transferred to a backboard, still in the prone position, for transport. He began vomiting, and his head was turned to the side to avoid aspiration. Shortly thereafter, the BLS personnel noted that the patient's breathing had slowed, followed quickly by apnea and pulselessness. The patient was immediately turned over, and an automated external defibrillator was applied that recommended "no shock." Cardiopulmonary resuscitation was commenced. Advanced life support personnel arrived 5 minutes after BLS personnel, and at that time, the patient was found to be in pulseless electrical activity (PEA). He was subsequently intubated and treated with $2 \mathrm{mg}$ of epinephrine and $100 \mathrm{mEq}$ of sodium bicarbonate intravenously over 4 minutes, following which he had return of spontaneous circulation.

On emergency department (ED) admission, the patient had a temperature of $35.9^{\circ} \mathrm{C}\left(96.6^{\circ} \mathrm{F}\right)$, blood pressure of $102 / 54 \mathrm{~mm} \mathrm{Hg}$, and a pulse of 89 beats/ min. His estimated weight was $85 \mathrm{~kg}$, and the resulting body mass index was calculated to be $23.3 \mathrm{~kg} / \mathrm{m}^{2}$. The patient was paralyzed and sedated. His physical examination was remarkable only for a small laceration on his nose and an abrasion on his left thigh. Laboratory investigations were notable for a normal potassium (4.1 mEq/L/4.1 mmol/L, ref. $3.5-5 \mathrm{mEq} / \mathrm{L} /$ $3.5-5 \mathrm{mmol} / \mathrm{L}$ ); a markedly elevated anion gap (35) and lactate $(>30 \mathrm{mmol} / \mathrm{L})$; and elevated creatinine $(1.7 \mathrm{mg} / \mathrm{dL} / 150.2 \mu \mathrm{mol} / \mathrm{L}$, ref. $0.7-1.3 \mathrm{mg} / \mathrm{dL} / 60$ $118 \mu \mathrm{mol} / \mathrm{L})$, glucose $(314 \mathrm{mg} / \mathrm{dL} / 17.4 \mathrm{mmol} / \mathrm{L}$, ref. 65-110 mg/dL/3.8-6 mmol/L), international normalized ratio (1.6), creatinine kinase (260 U/L), and myoglobin (1,527 ng/mL/87.19 nmol/L, ref. $17-$ $106 \mathrm{ng} / \mathrm{mL} / 1-6.05 \mathrm{nmol} / \mathrm{L})$. Troponin I was negative $(0.02 \mathrm{ng} / \mathrm{mL} / 0.02 \mu \mathrm{g} / \mathrm{L}$, ref. $<0.04 \mathrm{ng} / \mathrm{mL} /<0.04 \mu \mathrm{g} / \mathrm{L})$. An arterial blood gas measurement on ED admission revealed a $\mathrm{pH}$ of less than 6.8 , carbon dioxide partial pressure of $70 \mathrm{~mm} \mathrm{Hg}$, oxygen partial pressure of $348 \mathrm{~mm} \mathrm{Hg}$, and bicarbonate of $6 \mathrm{mEq} / \mathrm{L}(6 \mathrm{mmol} / \mathrm{L})$. A blood alcohol level and urine toxicology screening were negative. An electrocardiogram revealed sinus tachycardia without ischemic changes or signs of left ventricular hypertrophy. Peaked $\mathrm{T}$ waves were noted and subsequently resolved after treatment with $150 \mathrm{mEq}$ of sodium bicarbonate, $2 \mathrm{~g}$ of calcium gluconate, and $2 \mathrm{~L}$ of normal saline, all intravenously. He remained hemodynamically stable.

The patient was admitted to the intensive care unit with the diagnosis of primary metabolic acidosis after "PEA arrest likely secondary to Taser use." The patient was extubated on hospital day 3, although his course was complicated by ventilator-associated pneumonia. An echocardiogram on hospital day 5 showed normal left and right ventricular function and no evidence of valvular dysfunction. Evidence of hypoxic brain injury was diagnosed by magnetic resonance imaging on hospital day 20. The patient showed evidence of psychosis, with behavioural problems that resulted in a protracted inpatient course. A psychiatric consultant diagnosed him with schizophrenia, and treatment was initiated. Following a 110-day hospital admission, the patient was transferred to an outside psychiatric care facility for ongoing management.

\section{DISCUSSION}

During the past three decades, there has been increasing scrutiny of deaths in police custody, with research directed at ways to identify and respond appropriately to high-risk encounters. ${ }^{2,3}$ Deaths most frequently occur in association with forcible restraint and drug use, ${ }^{4}$ but no clear mechanism for these deaths has been found. The vast majority of restrained individuals in police custody do not suffer significant injury, 5 and among those who die, drug levels on autopsy are typically not in a lethal range when drugs 
are present. ${ }^{1}$ Research indicates that most who die in custody suffer from a constellation of symptoms referred to as ExDS, which is now recognized by many professional societies, including the American College of Emergency Physicians. ${ }^{6}$

Because ExDS can emerge from a number of underlying medical conditions, presentations during fatal encounters with law enforcement vary but frequently include behaviour seen with conditions such as cocaine or methamphetamine use. ${ }^{2}$ In addition to delirium and agitation, behaviours seen with ExDS include violence, paranoia, attraction to shiny objects, fear, shouting, guttural sounds, disrobing, resistance to restraint, superhuman strength, seeming imperviousness to pain, and sweating. Such patients are frequently found to be in a sympathomimetic state and may develop acidosis, rhabdomyolysis, and severe hyperthermia. ${ }^{1,4}$ Although none of these conditions invariably develops into a lethal state, some have suggested that a "perfect storm" may exist in fatal circumstances involving underlying medical conditions, severe acidosis and other toxic and metabolic abnormalities, a severe hyperactive stress response, and a restriction of normal compensatory mechanisms during a restraint position. ${ }^{7}$ The frequent use of conducted energy weapons in these cases has also been investigated for its contribution to the metabolic abnormalities and potential lethality. ${ }^{7}$

To our knowledge, the only other reported case of survival after ExDS-related cardiopulmonary arrest occurred in an ED. ${ }^{8}$ As in the case we report, this involved a patient with severe acidosis who responded shortly after intravenous sodium bicarbonate administration. Although empirical prehospital use of sodium bicarbonate treatment in the prehospital setting has been suggested, ${ }^{8}$ its administration is not routine. Prehospital use of sedatives and antipsychotics, which may be of benefit in patients with ExDS, is increasing but has not been prospectively studied. . $, 6,8,9$ Other care recommendations that may improve survival include a focus on minimizing the amount of and time in restrictive restraint while still ensuring that field personnel remain safe and early mobilization of advanced life support practitioners. Perhaps most importantly, education for both law enforcement officers and emergency medical services personnel, as occurs in our system, may help protect both patients and providers. Such training should include information to help personnel identify ExDS and emphasize the importance of rapid medical evaluation and potential treatments.
Controversy continues regarding restraint-related death and ExDS, in large part because of the limits of our knowledge about such events. The rarity of such events, in combination with the complex and vastly different circumstances under which they occur and frequent lack of medical evaluation prior to their occurrence, make appropriate data collection and interpretation challenging. As has been suggested by others, a national database of ExDS cases that included both survivors and nonsurvivors from the prehospital and ED setting would be valuable to define both the range of circumstances in which ExDS occurs and ways to minimize risk for those being restrained and care providers. ${ }^{1}$

\section{CONCLUSION}

We report a case of successful field resuscitation of an ExDS restraint-related cardiopulmonary arrest. Although it is unclear what, if any, features of this resuscitation contributed to the patient's survival, some are notable. The law enforcement agency involved is trained extensively on ExDS and the importance of early involvement of advanced life support personnel, which in this case allowed for rapid interventions when the patient arrested. In addition, the paramedic providers, who also receive training on ExDS, were aggressive in their management. Despite the presence of a severe lactic acidosis on ED admission, the patient recovered following prehospital treatment with advanced cardiac life support measures and intravenous sodium bicarbonate, likely in part due to early recognition of the disease process.

Competing interests: None declared.

\section{REFERENCES}

1. Vilke GM, Debard ML, Chan TC, et al. Excited delirium syndrome (ExDS): defining based on a review of the literature. f Emerg Med 2012;43:897-905, doi:10.1016/j.jemermed.2011. 02.017 .

2. Hughes EL. Special Panel review of excited delirium. Weapons \& Protective Systems Technologies Center Special Report; 2011.

3. Otahbachi M, Cevik C, Bagdure S, et al. Excited delirium, restraints, and unexpected death: a review of pathogenesis $\mathrm{Am}$ 7 Forensic Med Pathol 2010;31:107-12, doi:10.1097/PAF. 0b013e3181d76cdd.

4. Stratton SJ, Rogers C, Brickett K, et al. Factors associated with sudden death of individuals requiring restraint for excited delirium. Am 7 Emerg Med 2001;19:187-91, doi:10.1053/ ajem.2001.22665. 
5. Strote J, Verzemnieks E, Walsh M, et al. Use of force by law enforcement: an evaluation of safety and injury. 7 Trauma 2010;69:1288-93, doi:10.1097/TA.0b013e3181c45302.

6. Debard ML. White paper report on excited delirium syndrome. Dallas (TX): American College of Emergency Physicians; 2009.

7. Jauchem JR. Pathophysiologic changes due to TASER(R) devices versus excited delirium: potential relevance to deaths-in-custody?
7 Forensic Leg Med 2011;18:145-53, doi:10.1016/j.jflm.2011. 01.014 .

8. Hick JL, Smith SW, Lynch MT. Metabolic acidosis in restraint-associated cardiac arrest: a case series. Acad Emerg Med 1999;6:239-43, doi:10.1111/j.1553-2712.1999.tb00164.x.

9. Brice JH, Pirrallo RG, Racht E, et al. Management of the violent patient. Prehosp Emerg Care 2003;7:48-55, doi:10.1080/ 10903120390937085. 